\title{
Kinetic Approach to Biomineralization: Interactions of Synthetic Polypeptides with Calcium Carbonate Polymorphs ${ }^{\dagger}$
}

\author{
Branka Njegić-Džakula, ${ }^{a}$ Ljerka Brečević, ${ }^{a, *}$ Giuseppe Falini, ${ }^{b}$ and Damir Kralj ${ }^{a, *}$ \\ ${ }^{a}$ Laboratory for Precipitation Processes, Ruđer Bošković Institute, P. O. Box 180, HR-10002 Zagreb, Croatia \\ 'Dipartimento di Chimica "G. Ciamician", Università di Bologna, via Selmi 2, 40126 Bologna, Italy
}

RECEIVED DECEMBER 7, 2010; REVISED MARCH 4, 2011; ACCEPTED MARCH 17, 2011

\begin{abstract}
Biomineralization processes are the subject of numerous investigations. This article gives a review of the study on interactions between the charged polypeptides and the mineral surfaces involved in biomineralization, with an additional kinetic approach. The influence of polypeptides on two types of precipitation processes is discussed: the spontaneous precipitation from supersaturated solution and the growth kinetics of calcite seed crystals. In the first case the phenomenon of the formation and stabilization of metastable phases was found while in the second case the influence of the applied polypeptides on the kinetics and mechanisms of calcite crystal growth was investigated. Calcium carbonate polymorphs, calcite and vaterite, were used as biomineral substrates and acidic polypeptides, poly-L-aspartic (pAsp) acid and poly-L-glutamic (pGlu) acid, as simplified models of naturally occurring soluble acidic proteins. A basic polypeptide, poly-L-lysine (pLys), was also used in experiments in order to find out whether conformity between the crystal surface and the adsorbed polypeptide, or just the electrostatic interactions, have a decisive role in these processes. The addition of a particular polypeptide into the precipitation system caused a significant inhibition of nucleation and growth of vaterite, the extent of inhibition being in the order $\operatorname{Inh}_{\mathrm{pAsp}}>\mathrm{Inh}_{\mathrm{pGlu}}>>\mathrm{Inh}_{\mathrm{pLys}}$. In addition to the inhibition of precipitation, the change of the polymorphic composition and the crystal morphology of the precipitate were also achieved. The explanation of such acidic polypeptide behaviour is a consequence of kinetic constraints through the diverse efficiency of inhibition of both calcite nucleation and vaterite growth caused by adsorption of acidic polypeptides. The acidic polypeptides also caused the inhibition of calcite crystal growth, the effect being pAsp > pGlu, and changed the observed mechanism of growth controlled by the integration of ions into the spiral steps, as found for the model systems, to the surface nucleation rate-determining mechanism. Nonselective, weak and electrostatic adsorption of pLys at the crystal surface was probably responsible for increasing the calcite crystal growth rate when pLys was present at low concentrations and for inhibiting it at pLys higher concentrations. The strongest interactions between the crystal surfaces and the polypeptides, observed for the calcite/pAsp system, can account for coordinative interactions between the side chain carboxylic groups of the predominantly planar arrangement of the pAsp structure ( $\beta$-pleated sheet) and $\mathrm{Ca}^{2+}$ ions from the crystal surface. (doi: 10.5562/cca1809)
\end{abstract}

Keywords: calcium carbonate, calcite, vaterite, amorphous calcium carbonate, poly-L-aspartic acid, polyL-glutamic acid, poly-L-lysine

\section{OVERVIEW}

Biomineralization refers to the process by which the organisms deposit a mineral phase, which is usually indicated as biomineral. This term indicates not only the biogenic origin of the mineral, but also the fact that this product is a composite material of both mineral and organic components. Biominerals are actually agglomerates of mineral nano-crystals separated by biological macromolecules that can be inter- and/or intracrystalline. The relative amount of organic macromolecules can be as low as few percents. Biomineral phases often have properties such as shape, size, crystallinity, isotopic and trace element compositions quite unlike from its inorganically formed counterpart. Organisms are able to control their mineralization at molecular level producing materials with a hierarchical organization ranging from the nano- to the macro- scale. In many cases the control is achieved by means of biological (macro) molecules, which are usually gathered by the general term of organic matrix. The spatial and temporal organization of the organic matrix components is orchestrated at cellular level. This discriminates the degree of control over mineral deposition. Organic ma-

\footnotetext{
$\dagger$ This article belongs to the Special Issue Chemistry of Living Systems devoted to the intersection of chemistry with life.

* Authors to whom correspondence should be addressed. (E-mail addresses: brecevic@irb.hr; damir.kralj@irb.hr)
} 
trix components are usually studied after extraction from the biomineral and are historically classified in two families depending on their solubility in water solutions. ${ }^{1}$ In general, the soluble fraction is characterized by the presence of acidic macromolecules, which are rich in glutamic and aspartic acid residues in their proteic regions and usually sulphated in their glycosidic parts, sometimes the proteic regions are also phosphated. The insoluble fraction is usually formed by macromolecules able to build fibrous structures, like collagen in bones and chitin in mollusc shells, on which the soluble organic matrix adsorbs and may exert its function of control over mineral deposition. ${ }^{1}$ This classical distinction in some cases is not valid. Indeed, the same macromolecules can exert both roles in controlling their degree of aggregation, which is sometimes mediated by metal ions. ${ }^{2}$

It is a paradigm that biological processes mainly occur under kinetic control and that usually they are far from the thermodynamic equilibrium. The biomineralization processes respect this law. ${ }^{3}$ The organic matrix exerts its function controlling both the kinetics and the thermodynamics of mineral deposition. In a simplified view the kinetics control occurs by the stabilization of metastable phases that can be converted with the time in more stable ones or remain in this status for the lifetime of the organisms. The majority of all recent literature on biomineralization is addressed in the discovery and characterization of thermodynamically unstable mineral phases, usually amorphous phases, which can act as a precursor of the final (more) stable mineral form. ${ }^{4}$ However, thermodynamics also play an important role in biomineralization. The crystallography of biominerals is one of the most intriguing subjects of this theme. Organisms are able to specifically organize the crystalline units to build aggregates that diffract as single crystals, but with habit that are not subject to the limits imposed by the crystallographic symmetry. This may occur because there is a molecular recognition at the interface between the mineral phase and the organic matrix that is governed by a minimization of the interfacial energy, under thermodynamic control. ${ }^{5}$

This review presents the state of art of the research on the role of kinetics control on the deposition of calcium carbonate in the systems which have a great relevance for the general understanding of the biomineralization processes.

FORMATION OF CALCIUM CARBONATE POLYMORPHS AT SUPERSATURATION CONDITIONS RELEVANT TO THOSE IN BIOMINERALIZATION PROCESSES

The recent literature evidence ${ }^{6-10}$ emphasizes the role of less stable calcium carbonate $(\mathrm{CC})$ modifications in the formation of crystalline polymorphs. Thus, amorphous calcium carbonate (ACC) is suggested to be a precursor and the first solid phase precipitating within specialized cells involved in biomineralization. Indeed, ACC is used by some organisms (molluscs, sea urchins, corals and crustaceans) as a temporary storage substance for calcium and carbonate ions ${ }^{11-17}$ and supersaturation at which the biomineralization processes take place approximately corresponds to the ACC solubility value. Besides, it was also reported ${ }^{18,19}$ that in the precipitation systems in which vaterite was formed initially by a rapid precipitation under kinetic control, the formation of calcite was found to be a consequence of the solution-mediated transformation of vaterite. Because of the facts mentioned above, our experiments were designed so that the reference point for the chosen concentrations approximately corresponded to the ACC solubility. ${ }^{20}$

\section{Formation of Calcium Carbonate Polymorphs by Spontaneous Precipitation in the Absence of Synthet- ic Charged Polypeptides}

The initial solution supersaturation with respect to ACC, in the precipitation system prepared with equimolar concentrations of calcium and carbonate components at $25{ }^{\circ} \mathrm{C}$ was calculated and it was found that in the system $c_{\mathrm{i}}\left(\mathrm{Ca}^{2+}\right)=c_{\mathrm{i}}\left(\mathrm{CO}_{3}{ }^{2-}\right)=1.8 \times 10^{-3} \mathrm{~mol} \mathrm{dm}^{-3}$ the solution was in equilibrium with $\operatorname{ACC}\left(S_{\text {acc }}=1.00\right)$. The supersaturation was expressed as saturation ratio, $S=$ $\left(\Pi / K_{\mathrm{sp}}^{\mathrm{o}}\right)^{1 / 2}, K_{\mathrm{sp}}^{\mathrm{o}}$ or as relative supersaturation, $S-1$, where $\Pi$ is the ion activity product, $\Pi=a\left(\mathrm{Ca}^{2+}\right)$ $a\left(\mathrm{CO}_{3}{ }^{2-}\right)$, and $K_{\mathrm{sp}}^{\mathrm{o}}$ is the thermodynamic equilibrium constant of dissolution of the particular calcium carbonate modification (acc - amorphous calcium carbonate, v vaterite, $\mathrm{c}$ - calcite $)$ at $25^{\circ} \mathrm{C}\left(\mathrm{ACC}: K_{\mathrm{sp}}^{\mathrm{o}}=3.976 \times 10^{-7} ;^{-15}\right.$ vaterite: $K_{\mathrm{sp}}^{\mathrm{o}}=1.221 \times 10^{-8}$; calcite: $\left.K_{\mathrm{sp}}^{\mathrm{o}}=3.313 \times 10^{-9}\right)$. Two systems were chosen and examined as model systems: one undersaturated, $c_{\mathrm{i}}\left(\mathrm{Ca}^{2+}\right)=c_{\mathrm{i}}\left(\mathrm{CO}_{3}{ }^{2-}\right)=1.0 \times$ $10^{-3} \mathrm{~mol} \mathrm{dm}^{-3}\left(S_{\mathrm{acc}}=0.65, S_{\mathrm{c}}=7.1\right)$, and the other supersaturated, $c_{\mathrm{i}}\left(\mathrm{Ca}^{2+}\right)=c_{\mathrm{i}}\left(\mathrm{CO}_{3}{ }^{2-}\right)=2.5 \times 10^{-3} \mathrm{~mol} \mathrm{dm}^{-3}$ $\left(S_{\mathrm{acc}}=1.25, S_{\mathrm{c}}=13.7\right)$, with respect to ACC. The respective stability constants used for calculation of relevant ionic species are given in Ref. 21. The precipitates were characterized by X-ray powder diffraction (XRD), FT-IR spectroscopy, ${ }^{22}$ light and scanning electron microscopy. Figure 1 shows XRD patterns, FT-IR spectra (1000 to $600 \mathrm{~cm}^{-1}$ ) and scanning electron micrographs of the precipitates in the model systems of lower and higher initial supersaturations. Typical absorption bands characteristic of vaterite $\left(v_{4}=746 \mathrm{~cm}^{-1}\right)$ and calcite $\left(v_{4}=713 \mathrm{~cm}^{-1}\right)$ assigned as OCO bending (in-plane deformation) mode, as well as their XRD patterns undoubtedly demonstrate that the primary precipitate in the ACC-undersaturated model system (Figure 1a) consisted entirely of vaterite, while in the ACCsupersaturated model system (Figure 1b) a mixture of 
(a)
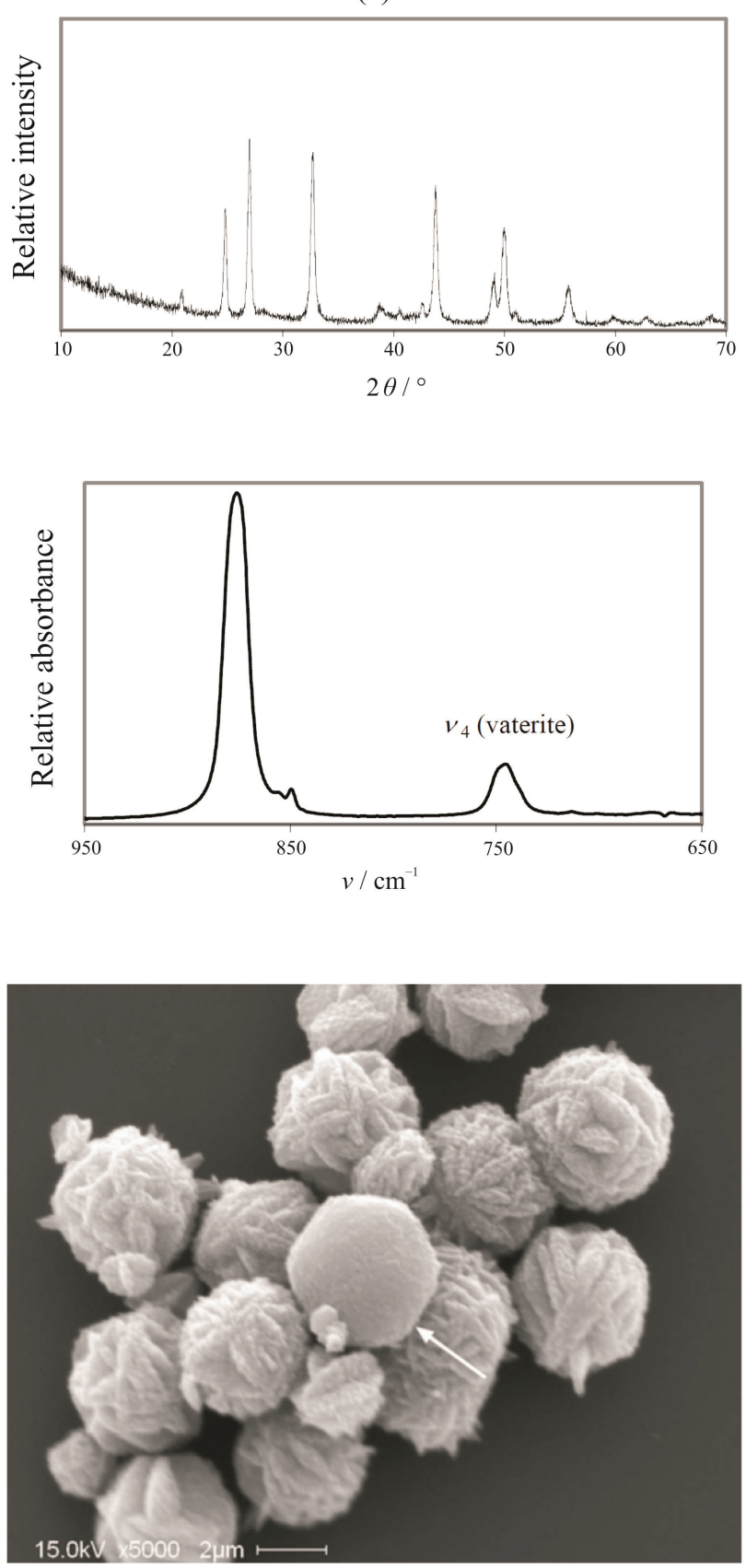

(b)
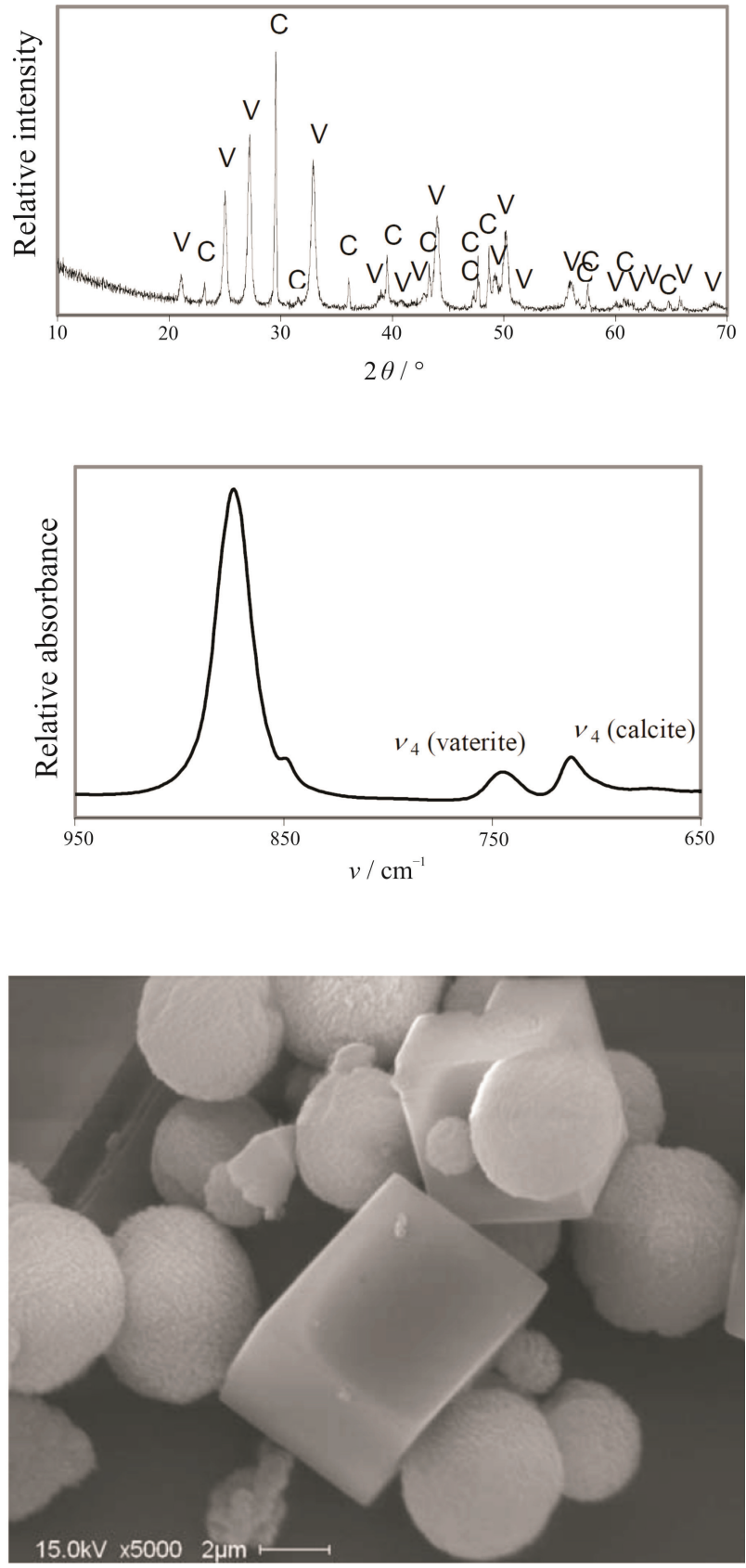

Figure 1. Characteristic parts of X-ray difractograms and FT-IR spectra, as well as scanning electron micrographs of calcium carbonates spontaneously precipitated in the model systems: (a) undersaturated $\left(c_{\mathrm{i}}\left(\mathrm{Ca}^{2+}\right)=c_{\mathrm{i}}\left(\mathrm{CO}_{3}{ }^{2-}\right)=1.0 \times 10^{-3} \mathrm{~mol} \mathrm{dm}^{-3}, S_{\mathrm{acc}}=\right.$ $\left.0.65, S_{\mathrm{c}}=7.1\right)$ and (b) supersaturated $\left(c_{\mathrm{i}}\left(\mathrm{Ca}^{2+}\right)=c_{\mathrm{i}}\left(\mathrm{CO}_{3}{ }^{2-}\right)=2.5 \times 10^{-3} \mathrm{~mol} \mathrm{dm}{ }^{-3}, S_{\text {acc }}=1.25, S_{\mathrm{c}}=13.7\right)$ with respect to amorphous calcium carbonate. Typical absorption bands of vaterite $\left(v_{4}=746 \mathrm{~cm}^{-1}\right)$ and calcite $\left(v_{4}=713 \mathrm{~cm}^{-1}\right)$ isolated 50 min after mixing reactant solutions, as well as their characteristic diffraction maxima marked with (v) for vaterite and with (c) for calcite, are shown. Arrow in SE micrograph 1a points out vaterite microaggregate in the form of a single hexagonal platelet aggregate.

calcite and vaterite was formed. Analogous results were obtained in our work in which kinetics of spontaneous precipitation of $\mathrm{CC}$ from moderately supersaturated solutions $\left(S_{\mathrm{acc}}=0.9\right)$ were studied. ${ }^{18}$ In the precipitation systems with higher supersaturations $\left(S_{\text {acc }}=3.1\right)$, the first appearing solid phase was ACC and calcite was formed at the end of the solution-mediated transformation that followed. ${ }^{23,24}$

Kinetic parameters needed for the comparison of the progress and extent of the precipitation processes between the model systems and those containing polypeptides were obtained by measuring $\mathrm{pH}$ of the solution 


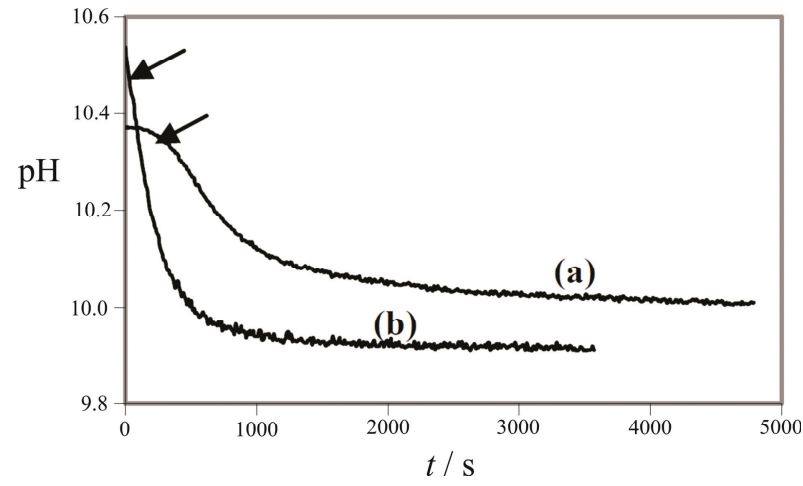

Figure 2. Typical progress curves, $\mathrm{pH} v s$. time, of the spontaneous precipitation of calcium carbonate at $25^{\circ} \mathrm{C}$ and different initial reactant concentrations: (a) $c_{\mathrm{i}}\left(\mathrm{Ca}^{2+}\right)=c_{\mathrm{i}}\left(\mathrm{CO}_{3}{ }^{2-}\right)=$ $1.0 \times 10^{-3} \mathrm{~mol} \mathrm{dm}{ }^{-3}$ and (b) $c_{\mathrm{i}}\left(\mathrm{Ca}^{2+}\right)=c_{\mathrm{i}}\left(\mathrm{CO}_{3}{ }^{2-}\right)=2.5 \times 10^{-3}$ mol dm${ }^{-3}$. The induction times are marked with arrows.

as a function of time. Figure 2 shows typical progress curves obtained for both model systems: (a) undersaturated and (b) supersaturated with respect to ACC. The induction periods elapsing between creation of supersaturation (mixing the reactants) and the first detectable solid phase were found to be approximately 5 and 0.5 min, respectively. The number density of particles formed initially in both model systems was of the order of $10^{7}$ per $\mathrm{cm}^{3}$, which pointed at heterogeneous nucleation being the prevailing mechanism of their formation.

Formation of Calcium Carbonate Polymorphs by Spontaneous Precipitation in the Presence of Synthetic Charged Polypeptides

In the model systems mentioned above, under supersaturation conditions that may be relevant to those of biomineralization processes, the effects of synthetic analogues of the proteic regions of acidic macromolecules from molluscs (polyamino acids: poly-L-aspartic, pAsp; poly-L-glutamic, pGlu; poly-L-lysin, pLys) were investigated. The addition of different concentrations of an acidic polypeptide, ${ }^{*} 0.1 \mathrm{ppm} \leq c_{\mathrm{i}}(\mathrm{pAsp}) \leq 2.0 \mathrm{ppm}$ of poly-L-aspartic acid or $0.2 \mathrm{ppm} \leq c_{\mathrm{i}}(\mathrm{pGlu}) \leq 2.0 \mathrm{ppm}$ of poly-L-glutamic acid, into the ACC-undersaturated precipitation system did not change the precipitate composition so that only vaterite precipitated, as was the case in the analogous model system. ${ }^{21}$ Still, these polyamino acids caused a significant inhibition of nucleation and crystal growth, which was reflected as an increase

\footnotetext{
* The average molar masses of polypeptides used were: $M_{\mathrm{r}}(\mathrm{pAsp})=11100 \mathrm{~g} \mathrm{~mol}^{-1}, M_{\mathrm{r}}(\mathrm{pGlu})=12300 \mathrm{~g} \mathrm{~mol}^{-1}$ and $M_{\mathrm{r}}(\mathrm{pLys})=8800 \mathrm{~g} \mathrm{~mol}^{-1}$ and the corresponding numbers of monomer units were 96,95 and 69, respectively. On account of the simplicity, the concentrations of polypeptides used in this research are given as parts per million (ppm).
}

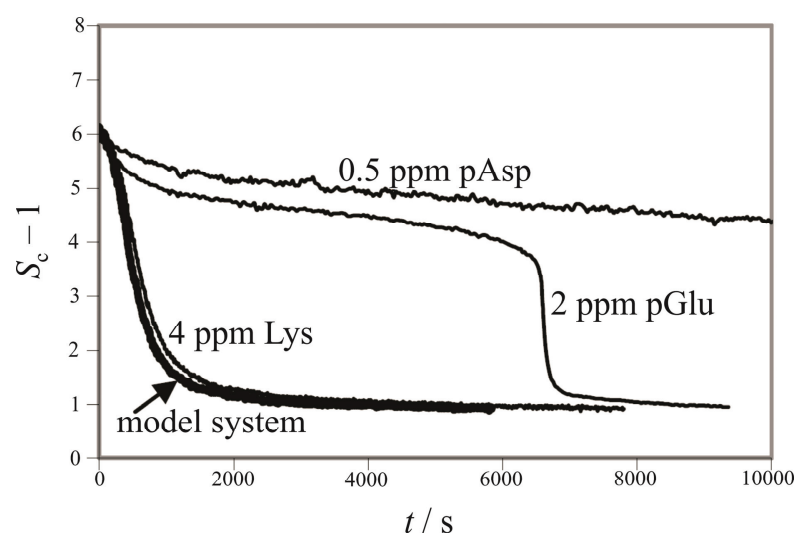

Figure 3. Progress curves, $S_{\mathrm{c}}-1$ versus time, of the model system $c_{\mathrm{i}}\left(\mathrm{Ca}^{2+}\right)=c_{\mathrm{i}}\left(\mathrm{CO}_{3}{ }^{2-}\right)=1.0 \times 10^{-3} \mathrm{~mol} \mathrm{dm}^{-3}$ and the analogous systems to which $0.5 \mathrm{ppm}$ pAsp, $2.0 \mathrm{ppm}$ pGlu and $4.0 \mathrm{ppm}$ pLys was added at $25^{\circ} \mathrm{C}$.

in induction period and formation of a so-called "dead zone" (apparent termination of crystal growth), respectively (see Figure 3 ). Thus, the retardation of vaterite nucleation occurred within the range $0.1 \mathrm{ppm} \leq c_{\mathrm{i}}(\mathrm{pAsp})$ $\leq 0.5 \mathrm{ppm}$ and in the whole range of pGlu concentrations used, causing an increase in induction period with the increase of polyamino acid concentration. A complete inhibition of nucleation was obtained only in the case of pAsp addition, i.e. at $c_{\mathrm{i}}(\mathrm{pAsp})>0.5 \mathrm{ppm}$. The presence of the basic polypeptide in the system, $0.2 \mathrm{ppm}$ $\leq c_{\mathrm{i}}(\mathrm{pLys}) \leq 4.0 \mathrm{ppm}$ of pLys, did not affect either nucleation or crystal growth significantly during the experiments. A strong agglomeration of vaterite particles, which was observed by light microscopy in the model system, was gradually reduced by the addition of increasing concentrations of polypeptides and was even completely prevented at their appropriate concentrations (e. g. at $c(\mathrm{pAsp})=0.25 \mathrm{ppm}){ }^{21}$ This suggests that polypeptides adsorb on the surface of vaterite particles thus preventing their interactions. Regarding the morphology of vaterite particles, scanning electron micrographs showed that the shape of the particles was not significantly affected by the addition of polypeptides in the given range of concentrations. Vaterite particles in all cases appeared mostly in the form of spherical structures composed of hexagonal platelet aggregates, the platelets rarely appeared even separately (see Figure 1a). The vaterite spherical particles were found earlier, by analysing broadening of their X-ray diffraction lines, to be aggregates of crystallites of $25-35 \mathrm{~nm}$ in size. ${ }^{25}$

Regarding the ACC-supersaturated system, the addition of acidic polypeptides caused a significant retardation of crystal growth and only the addition of pAsp changed the induction times noticeably (Figure 4). By the addition of different concentrations of pGlu or pLys, no significant changes in the induction time compared to the model system were observed; only pGlu caused changes of the dead zone. The observed retarda- 
Table 1. Initial polypeptide concentrations, $c / \mathrm{ppm}$, and experimentally determined mass fractions of calcite, $W_{\text {calcite, }}$ in the system of higher initial supersaturation, $S_{\mathrm{c}}-1=12.7 ; c_{\mathrm{i}}=\left(\mathrm{Ca}^{2+}\right)=c_{\mathrm{i}}\left(\mathrm{CO}_{3}{ }^{2-}\right)=2.5 \mathrm{mmol} \mathrm{dm}{ }^{-3}$

\begin{tabular}{clclcl}
\hline$c(\mathrm{pAsp}) / \mathrm{ppm}$ & $W_{\text {calcite }}$ & $c(\mathrm{pGlu}) / \mathrm{ppm}$ & $W_{\text {calcite }}$ & $c(\mathrm{pLys}) / \mathrm{ppm}$ & $W_{\text {calcite }}$ \\
\hline 0.0 & 0.23 & 0.0 & 0.23 & 0.0 & 0.23 \\
1.0 & 0.17 & 1.0 & 0.17 & 0.5 & 0.20 \\
2.0 & 0.17 & 2.0 & 0.18 & 2.0 & 0.15 \\
3.0 & 0.00 & 4.0 & 0.22 & 4.0 & 0.39 \\
4.0 & 0.00 & 5.0 & 0.09 & 7.0 & 0.03 \\
\hline
\end{tabular}

tion of crystal growth, caused by the addition of acidic polypeptides into the precipitation system, was explained according to the model of Cabrera and Vermilyea, ${ }^{26}$ which assumes contacts between the growing crystal and the adsorbed foreign molecules at the crystal surface.

The ACC-supersaturated system was also taken as a system suitable for investigation of the polypeptide influence on formation of CC polymorphs, since under the experimental conditions employed a mixture of two polymorphs (about $75 \%$ of vaterite and $25 \%$ of calcite) forms initially. It was found that the addition of pAsp or pGlu showed similar effect except that a higher concentration of pGlu was needed to reduce the content of calcite in the system (Table 1). pLys behaved differently from the acidic polypeptides. It even increased the mass fraction of calcite ( $\left.w_{\text {calcite }}\right)$ with increasing the concentration to a certain value but the further increase of its concentration decreased $w_{\text {calcite. }}$. The increase in $w_{\text {calcite }}$ could be explained by the enhancement of calcite crystal growth by pLys. $^{27}$ Such behaviour is typical for the molecules that bond non-selectively and weakly to the specific crystal surfaces and edges causing a decrease of the edge energy and an increase of the effective driving force.

Besides the effects that polypeptides exerted on the content and type of polymorphs in the precipitate,

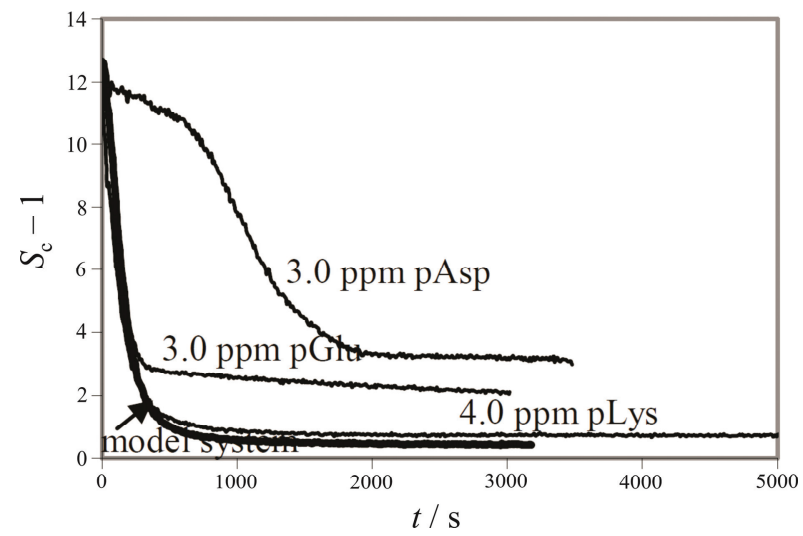

Figure 4. Progress curves, $S_{\mathrm{c}}-1$ versus time, of the model system $c_{\mathrm{i}}\left(\mathrm{Ca}^{2+}\right)=c_{\mathrm{i}}\left(\mathrm{CO}_{3}{ }^{2-}\right)=2.5 \times 10^{-3} \mathrm{~mol} \mathrm{dm}^{-3}$ and the analogous systems in the presence of $3.0 \mathrm{ppm}$ pAsp, $3.0 \mathrm{ppm}$ pGlu and $4.0 \mathrm{ppm}$ pLys at $25^{\circ} \mathrm{C}$. (a)

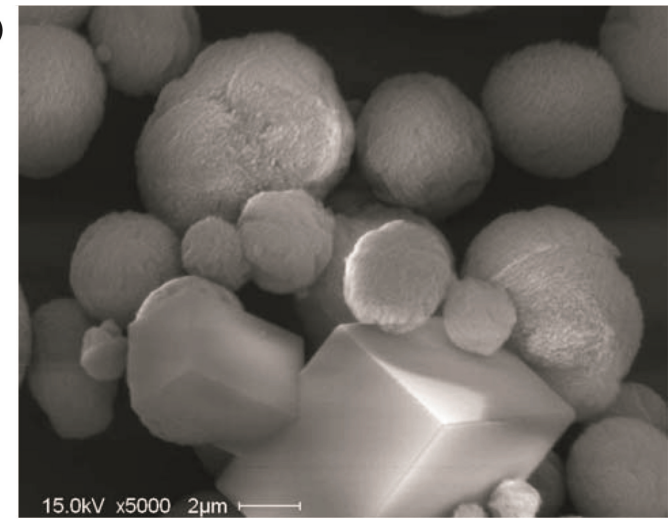

(b)

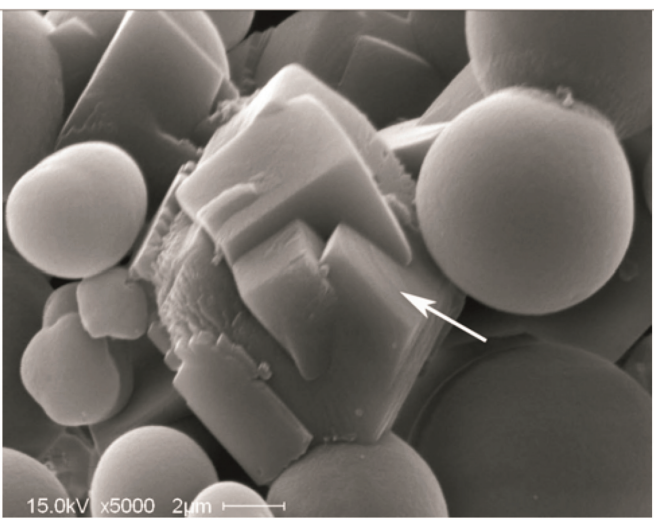

(c)

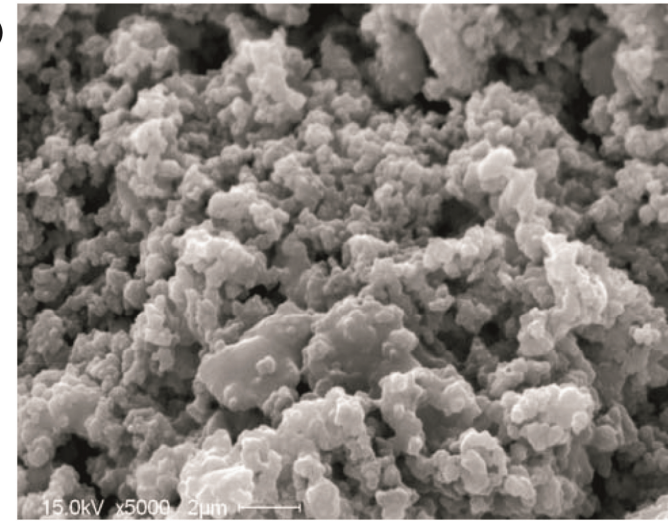

Figure 5. Scanning electron micrographs of the spontaneously precipitated calcium carbonate in the ACC-supersaturated system $\left(c_{\mathrm{i}}\left(\mathrm{Ca}^{2+}\right)=c_{\mathrm{i}}\left(\mathrm{CO}_{3}{ }^{2-}\right)=2.5 \times 10^{-3} \mathrm{~mol} \mathrm{dm}^{-3}, S_{\mathrm{c}}-1=12.7\right)$ and different concentrations of pAsp: (a) $0 \mathrm{ppm}$, (b) $1 \mathrm{ppm}$, and (c) $4 \mathrm{ppm}$. A new calcite face is pointed out with arrow. 
A

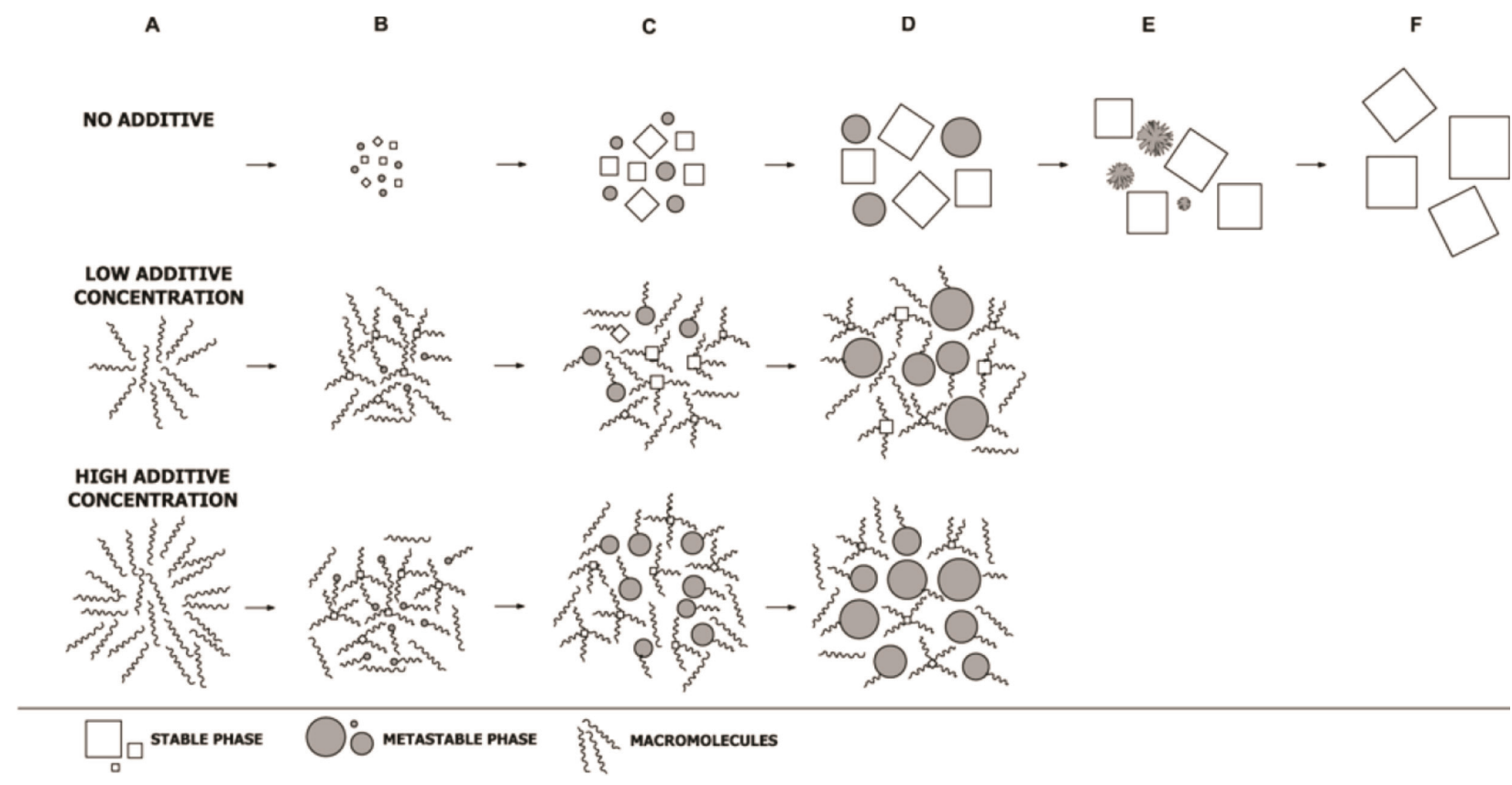

Scheme 1. The suggested model of interactions between the dissolved polypeptides (e.g.pAsp) and different solid substrates (e.g. metastable vaterite and thermodynamically stable calcite) that may nucleate and grow simultaneously in a precipitation system. (A) solution - prenucleation stage, (B) nucleation, (C, D) crystal growth of metastable and stable modifications, (E, F) solutionmediated transformation, which includes dissolution of metastable and crystal growth of thermodynamically stable phase.

pAsp also affected the morphology of both, vaterite and calcite. The typical shapes of vaterite rather regular spheres with rough surfaces and calcite regular rhombohedra, which were formed in the model system (Figure 5a), were changed to smooth vaterite spheres and calcite crystals with new faces and/or ledges (Figure 5b). The formation of new calcite faces or specifically oriented steps of the original $\{104\}$ crystalline faces are most probably the consequence of pAsp adsorption at the crystal surface. At pAsp concentrations at which the formation of calcite was prevented, vaterite appeared as much smaller microaggregates irregular in shape decreasing in size with increasing the pAsp concentration (Figure 5c).

Obviously, the acidic polypeptides, pAsp in particular, affected the nucleation, crystal growth and aggregation of $\mathrm{CC}$ polymorphs, which may be explained by taking into consideration relative strength and extent of interactions between the polypeptides and each of the polymorphs. A model that most probably represents the interactions between the two polymorphs, the thermodynamically metastable vaterite and the stable calcite that nucleate and grow simultaneously in the ACC-supersaturated system, and the dissolved polypeptide, like $\mathrm{pAsp}$, is represented in Scheme $1 .{ }^{21}$ When in the system without additives the solution becomes undersaturated with respect to the metastable phase, because of the growth of the stable phase, the solution-mediated transformation starts and lasts as long as the stable phase remains in equilibrium with the solution. The addition of an acidic polypeptide causes inhibition of nucleation and crystal growth of the stable polymorph, since it binds more strongly to the calcite than the vaterite surfaces. Consequently, the mass fraction of calcite and the amount of precipitate are reduced. If the polypeptide affects the morphology of both polymorphs, the formation of new crystal faces and/or ledges are expected. As a result of crystal growth and/or dissolution inhibition of the stable and metastable phases, the solution-mediated transformation of vaterite to calcite is also retarded. At the addition of certain higher concentrations of the polypeptide, the nucleation of calcite could be prevented, so that the solid phase will consist entirely of the metastable phase, vaterite.

The kinetic probability for the formation of the nuclei of any of the three CC polymorphs (vaterite, aragonite and calcite) could be presumed by the study of their crystalline structure. The $\mathrm{CO}_{3}{ }^{2-}$ ions in calcite (rhombohedral) and aragonite (orthorhombic) are perpendicular to the $c$-axis and calcium ions have sixfold and ninefold coordination, respectively. ${ }^{28,29}$ Since vaterite (hexagonal) structure has a certain degree of disorder (carbonate ions are randomly distributed over three orientations to the $c$-axis and calcium ions are in eightfold coordination) ${ }^{30}$ it needs fewer structural constraints than calcite and aragonite, the formation of vaterite nuclei should be kinetically favoured. 
It has also to be added that in both investigated systems, ACC-undersaturated and ACC-supersaturated, the nucleation was predominantly heterogeneous and the only difference between the systems was the impossibility for ACC to form in the ACC-undersaturated system. Because of that it springs to mind that the thermodynamically stable polymorph formation starts by the initial ACC nucleation and its subsequent transformation into calcite.

\section{SEEDED CRYSTAL GROWTH OF CALCITE IN THE PRESENCE OF SYNTHETIC POLYPEPTIDES}

The mechanisms of the processes involved in biomineralization, those occurring at the organic/inorganic interfaces in particular, are still the matter of study, in spite of the large amount of research performed on biomaterials and biomineralization. ${ }^{31-43}$ It has been suggested $^{4-46}$ that adsorption of organic macromolecules on the specific faces of crystals growing from solution retards their growth in the direction perpendicular to the particular face, which affects not only the crystal shape but also mechanical properties of thus formed composite material. Our investigations ${ }^{27}$ were focused on specific coordinative interactions between the synthetic acidic polypeptides (pAsp, pGlu) as analogues of biologically occurring soluble acidic proteins, and calcite as a mineral surface. In order to find out whether conformity between the substrate and the adsorbed polypeptides, or just nonspecific electrostatic interactions, play crucial role in biomineralization, the behaviour of pLys, the basic polypeptide with positively charged amino group side chains under the experimental conditions, was also investigated. From the results of kinetic data obtained in seeded experiments, the mode and extent of calcite/polypeptide interactions were determined.

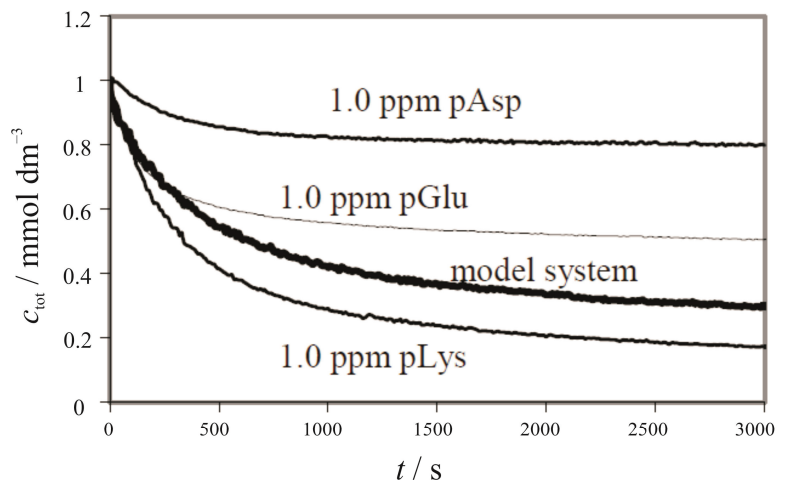

\section{Kinetics of Crystal Growth}

The crystal growth kinetic experiments were preformed under similar conditions of initial supersaturations, temperature $\left(25^{\circ} \mathrm{C}\right)$ and stirring rate as those of spontaneous precipitation. ${ }^{21}$ Two model systems were examined: in the lower supersaturation system the solution was undersaturated and in the higher supersaturation system the solution was supersaturated with respect to ACC. The initial mass concentrations of the calcite seed crystals introduced differed for the two systems $\left(\rho_{\text {seed }}=\right.$ $250 \mathrm{mg} \mathrm{dm}{ }^{-3}$ for the ACC-undersaturated system and $\rho_{\text {seed }}=1000 \mathrm{mg} \mathrm{dm}^{-3}$ for the ACC-supersaturated system), as well as the range of polypeptide concentrations $\left(0.3 \mathrm{ppm}<c_{\mathrm{i}}(\mathrm{pAsp}, \mathrm{pGlu})<1.5 \mathrm{ppm}\right.$ and $0.2 \mathrm{ppm}$ $<c_{\mathrm{i}}$ (pLys) $<4.0 \mathrm{ppm}$ for the ACC-undersaturated system and $0.7 \mathrm{ppm}<c_{\mathrm{i}}(\mathrm{pAsp}, \mathrm{pGlu})<2.05 \mathrm{ppm}$ and 0.5 $\mathrm{ppm}<c_{\mathrm{i}}$ (pLys) $<7.0 \mathrm{ppm}$ for the ACC-supersaturated system). It should be emphasized that, in order to provide the optimal reproducibility, the same batch of the calcite seed crystals was used for inoculation of solution in all experiments. ${ }^{27}$ The experiments were started by pouring $\mathrm{CaCl}_{2}$ solution into the same volume of $\mathrm{Na}_{2} \mathrm{CO}_{3}$ solution containing calcite seed crystals. In experiments in which polypeptides were present, an appropriate polypeptide concentration was also added to the carbonate component. As found earlier, the experiments performed under the same experimental conditions but without the addition of seed crystals into the system showed reproducible induction periods before the spontaneous precipitation started.

The propagation of the process was followed by the continuous $\mathrm{pH}$ measurements of the solution. On the basis of the $\mathrm{pH}$ measured and the known initial concentrations of the precipitating components, the solution composition at any moment of the calcite crystal growth was calculated. ${ }^{27}$ The detailed calculation procedure, which takes into account the respective protolytic equilibria and equilibrium constants, as well as the charge

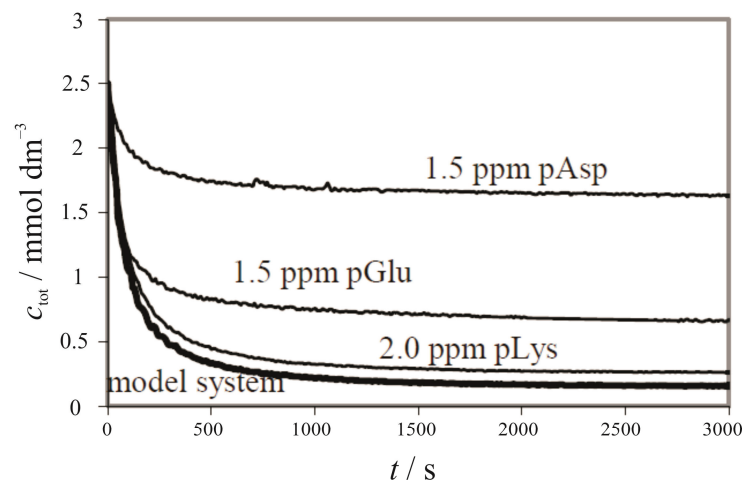

Figure 6. Progress curves, $c_{\text {tot }}$ versus time, of the seeded calcite growth at $25{ }^{\circ} \mathrm{C}$ in two different model systems: (a) $c_{\mathrm{i}}\left(\mathrm{Ca}^{2+}\right)=$ $c_{\mathrm{i}}\left(\mathrm{CO}_{3}{ }^{2-}\right)=1.0 \times 10^{-3} \mathrm{~mol} \mathrm{dm}{ }^{-3}$ and calcite seed mass $\rho$ (calcite) $=250 \mathrm{mg} \mathrm{dm}^{-3}$; (b) $c_{\mathrm{i}}\left(\mathrm{Ca}^{2+}\right)=c_{\mathrm{i}}\left(\mathrm{CO}_{3}{ }^{2-}\right)=2.5 \times 10^{-3} \mathrm{~mol} \mathrm{dm}^{-3}$ and calcite seed mass $\rho$ (calcite) $=1000 \mathrm{mg} \mathrm{dm}^{-3}$, as well as in the analogous systems in the presence of: (a) $1.0 \mathrm{ppm}$ pAsp, 1.0 ppm pGlu or 1.0 ppm pLys, and (b) 1.5 ppm pAsp, 1.5 ppm pGlu or 2.0 ppm pLys. 
and mass balance equations can be found in any of previous papers. ${ }^{18,23,24,47,48}$ The progress curves, $c_{\text {tot }}$ versus time, of both model systems, and those recorded in the presence of $1.0 \mathrm{ppm}$ of pAsp, pGlu, and pLys, are shown in Figure 6. By the addition of each of pAsp or pGlu, a retardation of crystal growth of calcite was achieved. That was demonstrated by lowering the slope of the respective progress curves with increasing the polypeptide concentrations (not all curves are shown in Figure 6). This tendency was comparable for the both polypeptides although the effect of pAsp was more pronounced than the effect of pGlu and the termination of crystal growth apparently happened at different supersaturation levels. In the case of pLys addition, an enhanced of the growth rate of calcite in the ACCundersaturated system was observed even at concentrations lower than $1.0 \mathrm{ppm}$. The effect was manifested as a faster drop in $c_{\text {tot }}$ compared to the model system. On the contrary, in the case of ACC-supersaturated system, the addition of as much as $7.0 \mathrm{ppm}$ of pLys did not affect the kinetics of the calcite crystal growth to a great extent, as observed from the shape of the respective progress curves.

The calcite crystal growth rates, $-\mathrm{d}[\mathrm{Ca}]_{\text {tot }} / \mathrm{d} t$, were calculated by numerical differentiation of the total dissolved calcium concentration, $[\mathrm{Ca}]_{\text {tot }}$, as a function of time, $t$, and was expressed as a function of supersaturation at a particular moment:

$$
v_{\mathrm{g}}=-\mathrm{d}[\mathrm{Ca}]_{\mathrm{tot}} / \mathrm{d} t=k_{n} c_{\mathrm{ppt}}^{2 / 3}(S-1)^{n}
$$

In the above equation $k_{n}$ is the rate constant and $c_{\mathrm{ppt}}$ is the concentration of precipitated calcium carbonate, which was determined by subtracting the calculated total concentration of calcium or carbonate species from the known initial calcium chloride, $\left[\mathrm{CaCl}_{2}\right]_{\mathrm{i}}$, or sodium carbonate, $\left[\mathrm{Na}_{2} \mathrm{CO}_{3}\right]_{i}$, concentration.

In order to study the influence of the chosen polypeptides on the calcite crystal growth kinetics and mechanisms, the respective growth rates, $\mathrm{d} c / \mathrm{d} t$, calculated from the progress curves of the model systems and the systems with a polypeptide added, were plotted as a function of relative supersaturation. After testing different theoretical crystal growth models, parabolic and exponential, respectively:

$$
\begin{aligned}
\mathrm{d} c / \mathrm{d} t= & k_{2} c_{\mathrm{ppt}}{ }^{2 / 3}(S-1)^{2} \\
\mathrm{~d} c / \mathrm{d} t= & k_{\mathrm{e}} S^{7 / 6}(S-1)^{2 / 3}(\ln S)^{1 / 6} \exp \left[-K_{\mathrm{e}} / \ln S\right]= \\
& k_{\mathrm{e}} F(S) \exp \left[-K_{\mathrm{e}} / \ln S\right]
\end{aligned}
$$

the straight lines obtained indicated the mechanism of the basic reaction that controlled the calcite growth (rate determining reaction) at the given experimental condi-

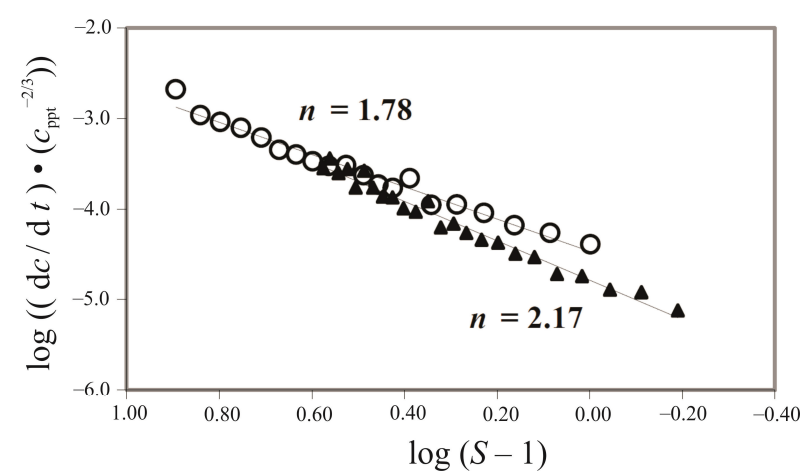

Figure 7. Logarithmic plots of growth rates $v s$. relative supersaturation, in accordance with Eq. (2), of the seeded calcite growth at $25{ }^{\circ} \mathrm{C}$ in two different model systems: (a) $c_{\mathrm{i}}\left(\mathrm{Ca}^{2+}\right)=$ $c_{\mathrm{i}}\left(\mathrm{CO}_{3}{ }^{2-}\right)=1.0 \times 10^{-3} \mathrm{~mol} \mathrm{dm}{ }^{-3}$ and calcite seed mass $\rho$ (calcite $)=250 \mathrm{mg} \mathrm{dm}^{-3}$; (b) $c_{\mathrm{i}}\left(\mathrm{Ca}^{2+}\right)=c_{\mathrm{i}}\left(\mathrm{CO}_{3}{ }^{2-}\right)=2.5 \times 10^{-3} \mathrm{~mol}$ $\mathrm{dm}^{-3}$ and calcite seed mass $\rho$ (calcite) $=1000 \mathrm{mg} \mathrm{dm}^{-3}$, giving slopes (rate orders) $n=2.17$ and $n=1.78$, respectively.

tions. The growth kinetics for the both model systems were found to obey the parabolic rate law indicating that the calcite growth rate was controlled by a second order surface reaction, i.e. the integration of ions into the spiral step emerging from the surface dislocation. Figure 7 shows logarithmic plots of the growth rate $v s$. relative supersaturation for the ACC-undersaturated and ACCsupersaturated model systems giving slopes (rate orders) $n=2.17$ and $n=1.78$, respectively, which are consistent with the reports of some other authors. ${ }^{24,49-51}$ The respective rate constants were also determined: $k_{2}=$ $2.373 \times 10^{-5} \pm 0.15 \times 10^{-5} \mathrm{~mol}^{1 / 3} \mathrm{dm}^{-1} \mathrm{~s}^{-1}$ for the ACCundersaturated system, and $k_{2}=2.03 \times 10^{-5} \pm 0.15 \times$ $10^{-5} \mathrm{~mol}^{1 / 3} \mathrm{dm}^{-1} \mathrm{~s}^{-1}$ for the ACC-supersaturated system. By the addition of different concentrations of each of the polypeptide used, an inhibition of the calcite crystal growth was observed, as well as the change of the rate controlling mechanism. The straight lines obtained for the exponential rate law indicated that the addition of pAsp and pGlu in the ACC-undersaturated and ACCsupersaturated systems, as well as the addition of pLys to the ACC-undersaturated system resulted in the change of the rate controlling mechanism from integration of growth units into the spiral step (parabolic law) in the model systems to the surface nucleation controlled growth (exponential law). The appropriate crystal growth rate constants of calcite for the ACCundersaturated systems were determined to be: $k_{2}=$ $2.49 \times 10^{-5} \mathrm{~mol}^{1 / 3} \mathrm{dm}^{-1} \mathrm{~s}^{-1}$ for pAsp, $k_{2}=2.20 \times 10^{-5}$ $\mathrm{mol}^{1 / 3} \mathrm{dm}^{-1} \mathrm{~s}^{-1}$ for pGlu and $k_{2}=2.43 \times 10^{-5} \mathrm{~mol}^{1 / 3}$ $\mathrm{dm}^{-1} \mathrm{~s}^{-1}$ for pLys. For the ACC-supersaturated systems the respective constants were found to be: $k_{2}=1.96 \times$ $10^{-5} \mathrm{~mol}^{1 / 3} \mathrm{dm}^{-1} \mathrm{~s}^{-1}, k_{2}=1.81 \times 10^{-5} \mathrm{~mol}^{1 / 3} \mathrm{dm}^{-1} \mathrm{~s}^{-1}$ and $k_{2}=1.30 \times 10^{-5} \mathrm{~mol}^{1 / 3} \mathrm{dm}^{-1} \mathrm{~s}^{-1}$ for pAsp, $k_{2}=2.21 \times$ $10^{-5} \mathrm{~mol}^{1 / 3} \mathrm{dm}^{-1} \mathrm{~s}^{-1}$ and $k_{2}=1.40 \times 10^{-5} \mathrm{~mol}^{1 / 3} \mathrm{dm}^{-1} \mathrm{~s}^{-1}$ for pGlu, and $k_{2}=1.94 \times 10^{-5} \mathrm{~mol}^{1 / 3} \mathrm{dm}^{-1} \mathrm{~s}^{-1}, k_{2}=1.66 \times$ 


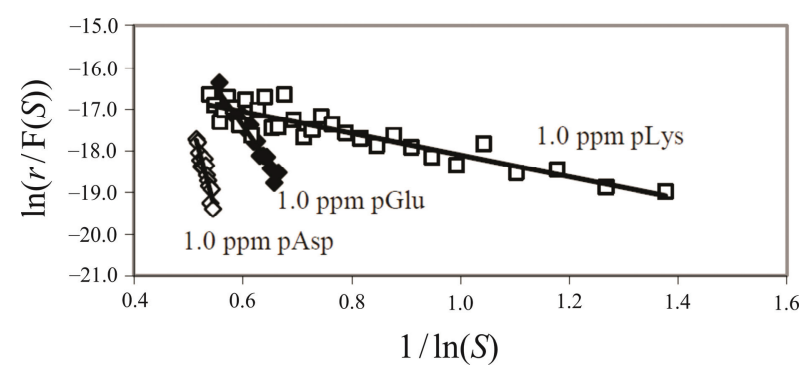

Figure 8. Test plots for the exponential rate law, according to Eq. (3), of the calcite crystal growth at $25{ }^{\circ} \mathrm{C}$ in the ACCundersaturated system, $c_{\mathrm{i}}\left(\mathrm{Ca}^{2+}\right)=c_{\mathrm{i}}\left(\mathrm{CO}_{3}{ }^{2-}\right)=1.0 \times 10^{-3} \mathrm{~mol}$ $\mathrm{dm}^{-3}$, containing concentrations of $1.0 \mathrm{ppm}$ of pAsp, pGlu and pLys.

$10^{-5} \mathrm{~mol}^{1 / 3} \mathrm{dm}^{-1} \mathrm{~s}^{-1}, k_{2}=1.69 \times 10^{-5} \mathrm{~mol}^{1 / 3} \mathrm{dm}^{-1} \mathrm{~s}^{-1}$, $k_{2}=1.71 \times 10^{-5} \mathrm{~mol}^{1 / 3} \mathrm{dm}^{-1} \mathrm{~s}^{-1}$ and $k_{2}=1.92 \times 10^{-5}$ $\mathrm{mol}^{1 / 3} \mathrm{dm}^{-1} \mathrm{~s}^{-1}$ for pLys. As seen from these data, the change in the rate determining mechanism of the ACCsupersaturated system, caused by the presence of polypeptides, was less evident. The most likely explanation is an increase in the surface area of the available calcite seed crystals (ACC-undersaturated system: $\rho_{\text {seed }}=250$ $\mathrm{mg} \mathrm{dm}{ }^{-3}$ and ACC-supersaturated system: $\rho_{\text {seed }}=1000$ $\mathrm{mg} \mathrm{dm}^{-3}$ ), that caused the proportionally lower coverage of the adsorption sites. Figure 8 shows test plots for the exponential rate law of the calcite crystal growth in the ACC-undersaturated system containing concentrations of $1.0 \mathrm{ppm}$ pAsp, pGlu and pLys. The change in crystal growth controlling mechanism could be explained by assuming that the growth at the surface spirals and surface nucleation are the processes taking place simultaneously. At such conditions, the overall growth rate totals the individual rates and, when one process is significantly inhibited, it could be approximated that the faster process is the rate determining one. However, by stopping growth through the adsorption of polypeptide molecules onto a limited number of active kinks at the spiral step, surface nucleation could become the rate determining process, even at relatively low supersaturation.

The influence of selected polypeptides on crystal growth of calcite was further investigated by analyzing the growth rate kinetics with respect to the polypeptide concentration and supersaturation of the system. It was found that the addition of pGlu and pAsp caused termination of calcite growth (dead zone) at the respective critical supersaturations, $S^{*}$, which increased with increasing their concentrations in the system. On the instance of pGlu, Figure 9 shows typical curves of calcite crystal growth rates, corrected for the change in the surface area of calcite seed crystals $\left(-\left(\mathrm{d}[\mathrm{Ca}]_{\mathrm{tot}} / \mathrm{d} t\right) c_{\mathrm{ppt}}^{-2 / 3}\right)$, as a function of relative supersaturation in the ACC-undersaturated precipitation system. It is evident that at $c(\mathrm{pGlu})=0.3 \mathrm{ppm} S^{*}=$ 1.8 and at $c($ pGlu $)=0.8 \mathrm{ppm} S^{*}$ increased to $S^{*}=4.0$.

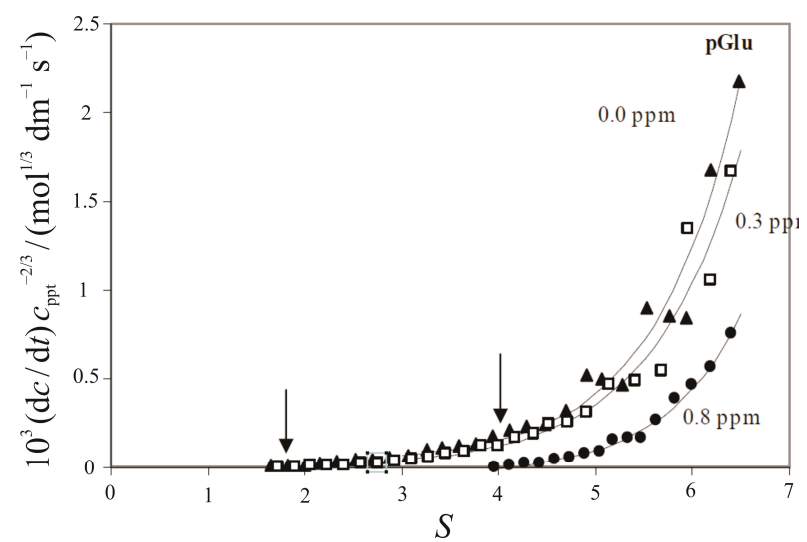

Figure 9. Crystal growth rate of calcite seed as a function of relative supersaturation in the ACC-undersaturated system, $c_{\mathrm{i}}\left(\mathrm{Ca}^{2+}\right)=c_{\mathrm{i}}\left(\mathrm{CO}_{3}{ }^{2-}\right)=1.0 \times 10^{-3} \mathrm{~mol} \mathrm{dm}{ }^{-3}$ at $25{ }^{\circ} \mathrm{C}$ upon addition of different concentrations of pGlu. Arrows indicate the values of $S^{*}$.

According to the model of Cabrera and Vermilyea, ${ }^{26}$ the termination of crystal growth at a certain polypeptide concentration can be explained as a consequence of its adsorption on the crystal terrace (ledge). ${ }^{52}$ The advancing step (ledge) will stop at a certain supersaturation when the distance between the adsorbed molecules becomes smaller than the diameter of the critical surface nucleus. If the distance is larger than the diameter, the step (ledge) will curl around the molecules, which will slow down the crystal growth and change the crystal morphology. Figure 10 shows SEM images of the calcite crystals taken from the model system (Figure 10a) and the systems after overgrowth in the presence of pAsp, pGlu and pLys (Figures 10bd). The curved edges of crystals obtained in the presence of the acidic polypeptides suggest the presence of new stabilized crystalline faces, which are different from the stable $\{104\}$ faces. Their appearance is most probably a consequence of the adsorption of the particular polypeptide by matching between the charged carboxylate groups and the calcium ions from the crystal surface. Since the accurate indexing of these curved faces was not possible, it could also be considered as an option that the curved edges are specifically oriented steps of the $\{104\}$ crystalline faces. It was reported that in the adsorbed state pAsp assumed $\beta$-sheet and random coil conformation, while pGlu was in $\alpha$-helix and random coil conformation. ${ }^{53}$ Similarly to the proposed conclusions, the calcite crystal edges were found to be rounded on the addition of proteins involved in deposition of calcitic prismatic layer of mollusc shells. These highly charged glycoproteins rich in aspartic acid and therefore called Asprich, contain $>50 \%$ of aspartic acid enriched sequences, including the polyaspartic acid sequences. $^{54}$ 
(a)

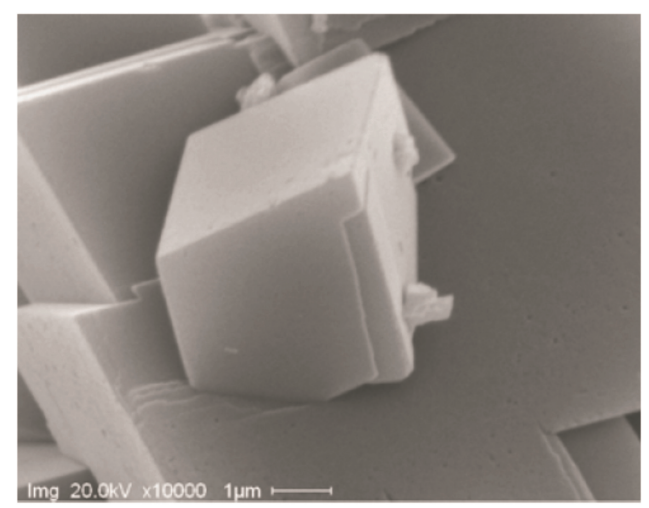

(c)

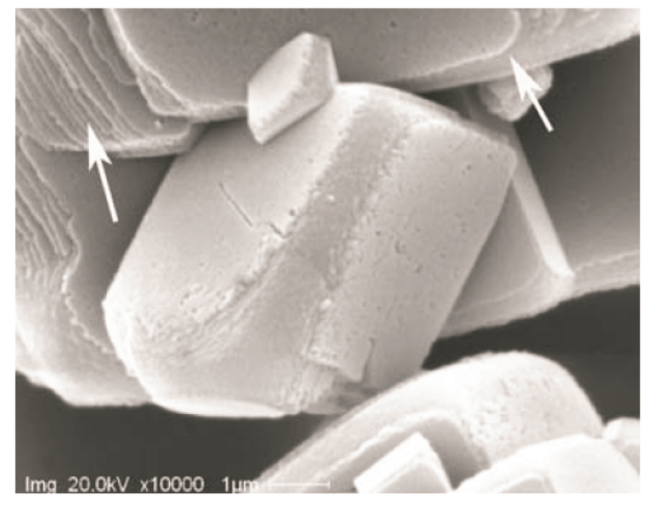

(b)

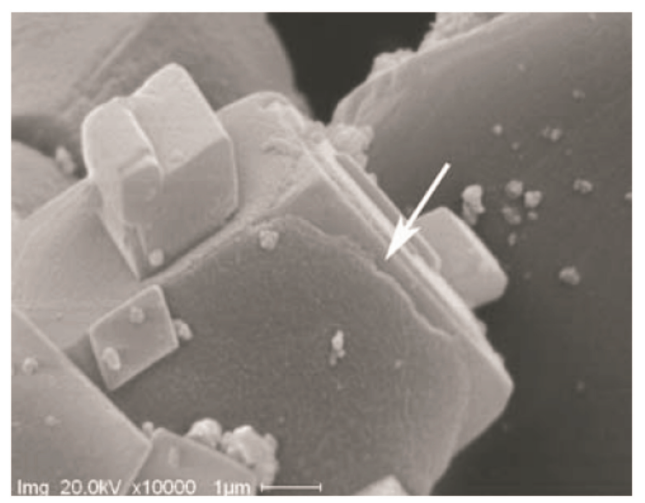

(d)

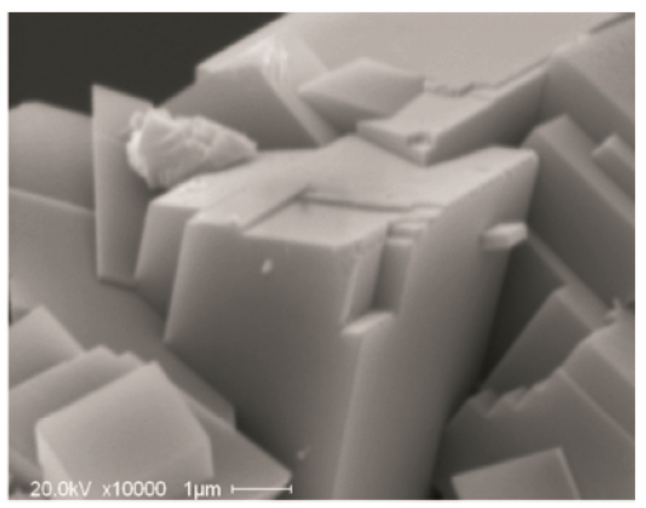

Figure 10. Scanning electron micrographs of calcite crystals after overgrowth experiments in the model system (a), and in the presence of pAsp (b), pGlu (c) and pLys (d). Some of the curved edges of overgrown layers (b, c) are marked with arrows.

In distinction from $\mathrm{pAsp}$ and pGlu, the addition of basic polypeptide pLys into the system did not cause the formation of dead zone of calcite growth. This indicates a different mode of polypeptide/crystal surface interaction. At the same time, the morphology of calcite crystals grown in the presence of pLys did not show any significant change in the crystal shape compared to the model system (see Figures 10a and 10d) thus indicating that no additional stabilized crystalline faces were formed.

The quantitative estimation and comparison of the effects of selected polypeptides on the crystal growth rate of calcite were made by using model of Kubota and Mullin. ${ }^{55}$ The model correlates the reduction of crystal growth rate in the presence of inhibitors with their concentrations and is described by the equation

$$
v / v_{0}=1-\alpha \theta_{\text {eq }}=1-[\alpha K c /(1+K c)]
$$

where $v / v_{0}$ is the reduction of the crystal growth rate $(v$ is the growth rate in the polypeptide containing system, and $v_{0}$ is the growth rate in the model system at the given supersaturation), $c$ is the additive concentration, $K$ is the Langmuir constant, $\alpha$ is the effectiveness of poly- peptide and $\theta_{\text {eq }}$ is the crystal surface coverage. Figure 11 shows the plots of the relative crystal growth rate reduction of calcite seeds, $v / v_{0}$, as a function of different polypeptide concentrations for relative supersaturation, $S-1=5.5$ in the ACC-undersaturated system. A range of relative supersaturations were analyzed (not all shown here) and different growth reduction patterns were obtained. The results directly depended on the type

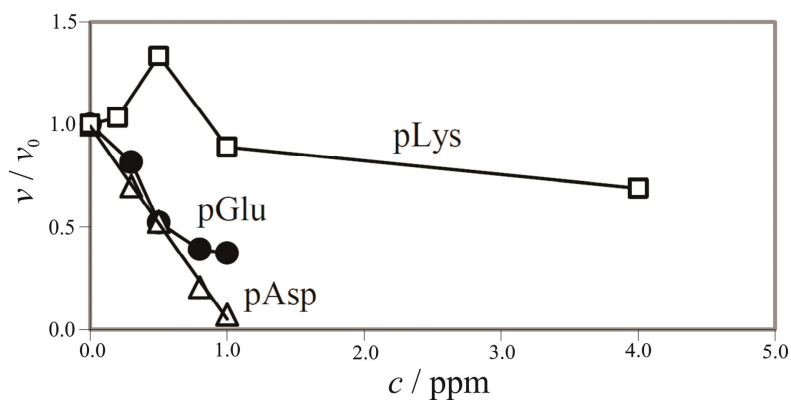

Figure 11. Relative crystal growth rate reduction, $v / v_{0}$, of calcite seeds in the ACC-undersaturated system, $c_{\mathrm{i}}\left(\mathrm{Ca}^{2+}\right)=$ $c_{\mathrm{i}}\left(\mathrm{CO}_{3}{ }^{2-}\right)=1.0 \times 10^{-3} \mathrm{~mol} \mathrm{dm}{ }^{-3}$, at $25^{\circ} \mathrm{C}$ and relative supersaturation, $S-1=5.5$, as a function of different polypeptide concentrations. 

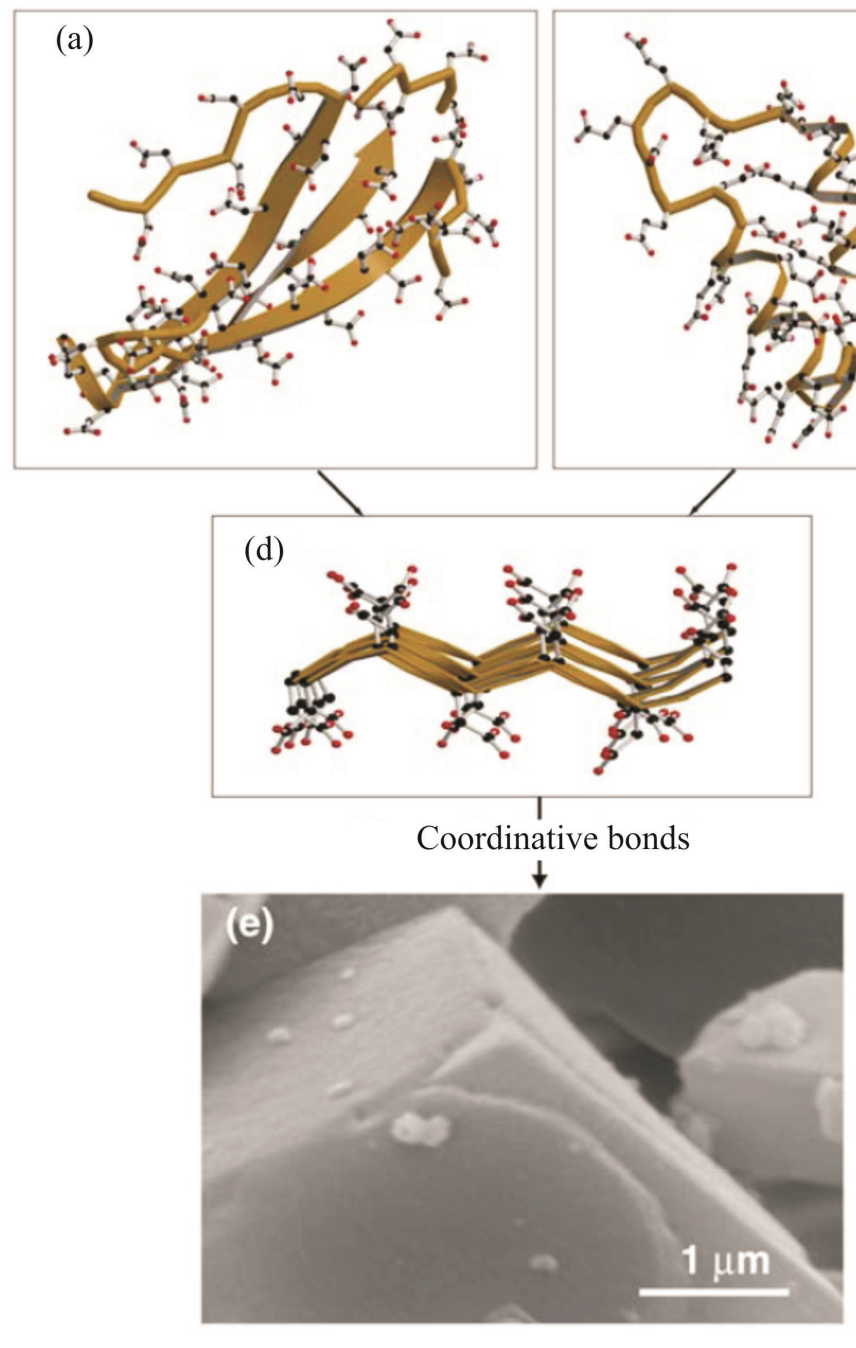

(b)

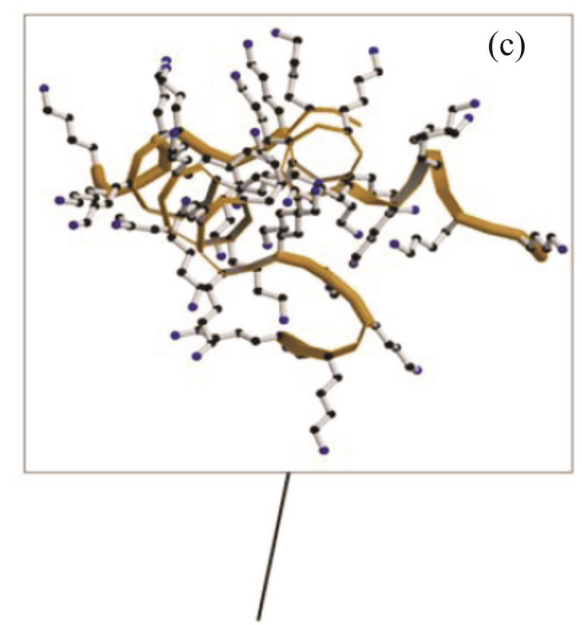

Electrostatic Interactions

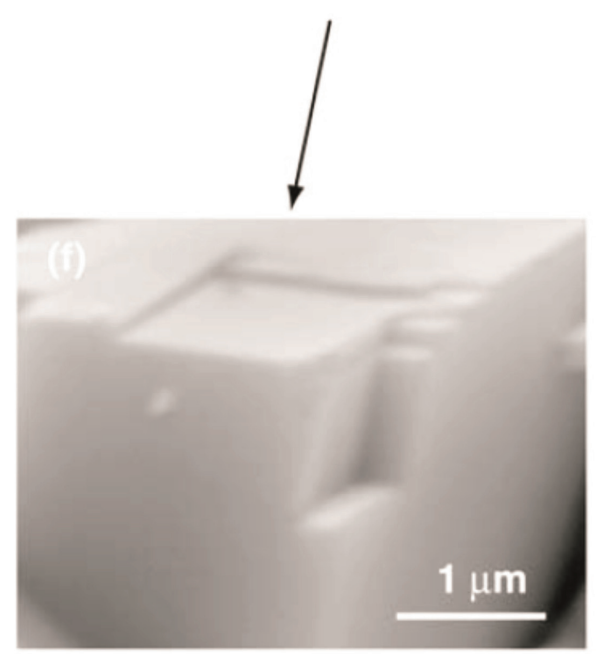

Scheme 2. Schematic model of possible interactions between the carboxylic groups from the side chains of acidic polypeptides adopting random coil (pGlu) or partial $\beta$-pleated sheet conformation (pAsp) and crystal sites.

of polypeptide used. In the case of pAsp, $v / v_{0}$ linearly decreased to zero at all supersaturations, pGlu caused a progressive reduction of $v / v_{0}$, which apparently asymptotically approached a certain nonzero values, while pLys caused a growth rate enhancement at its lower concentrations and higher solution supersaturations $(S-$ $1>5.5)$, as well as the growth rate decrease at lower solution supersaturations $(S-1<5.0)$ and increase of its concentration. Such behaviour is typical for the additives that weakly and nonselectively bond to the crystal surface. Their interactions are most probably of electrostatic nature and have no ability of stabilizing specific new crystalline faces with respect to the energetically favoured $\{104\}$ ones. The enhancement of growth rate can be explained by the adsorption of mobile molecules at the steps, causing a decrease of edge energy and the related increase of the effective driving force of crystal growth. ${ }^{52}$ It was reported in the literature that the growth rate enhancement in the presence of selected oligopep- tides $\left(\left(\mathrm{Asp}_{3} \mathrm{Gly}\right)_{6} \mathrm{Asp}_{3},\left(\mathrm{Asp}_{3} \mathrm{Ser}\right)_{6} \mathrm{Asp}_{3}\right.$, Asp-Glu, etc. $)$ was observed at very low, nanomolar, concentrations. ${ }^{56-58}$ Considering that the supersaturations investigated in this work were higher, the crystal growth could occur not only at the spiral steps but also through the surface nucleation mechanism.

The inhibitory effectiveness, $\alpha$, of pGlu and pAsp can be directly compared, if it is assumed that their adsorption is a result of coordinative bonds between the carboxylic groups from their side chains and calcium ions at the crystal surface. Their primary structures are also similar, differing only in one carbon atom, which refers to the similar Langmuir constants, $K$. Based on the analytical expression for the growth rate reduction (Eq. (4)) and on the facts mentioned above, it can be concluded that $\alpha_{\mathrm{pAsp}}>\alpha_{\mathrm{pGlu}}$. The likely explanation lies in their stereochemical difference. In a solution containing $\mathrm{Ca}^{2+}$ ions, and particularly when adsorbed on surfaces, pAsp tends to adopt more extended regions in $\beta$ - 
(a)

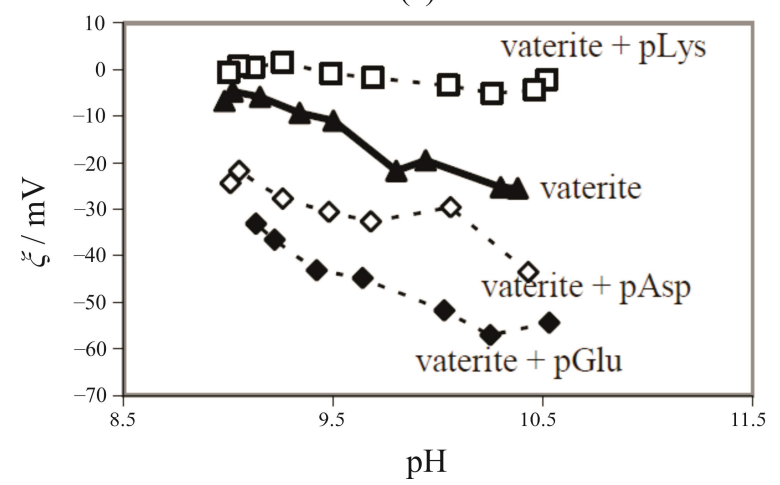

(b)

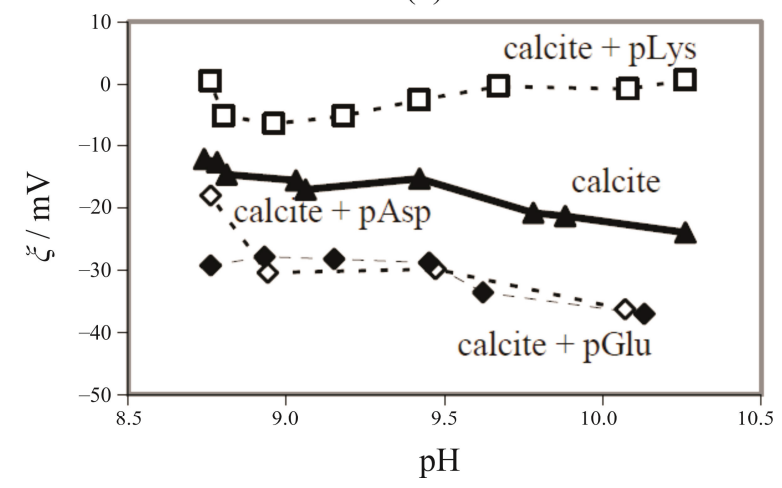

Figure 12. $\zeta$-potential of vaterite (a) and calcite (b) seeds dispersed in solutions containing 2 ppm of pAsp, pGlu or pLys as a function of $\mathrm{pH}$.

pleated sheet conformation, while pGlu conserves $\alpha$ helix and random coil conformations, and to a lesser extent the $\beta$-pleated sheet conformation of some distinct regions. ${ }^{59}$ The extended conformation that the polypeptide assumes in the $\beta$-sheet region favours the formation of more coordinative bonds. These chemical bonds can initiate the formation and stabilization of new crystalline $\{h k l\}$ faces simply by preventing the formation and/or development of thermodynamically stable faces.

The model of strong coordinative interactions between pAsp and calcite surface is complementary to the mechanism described for functioning of the Asprich proteins. For that, it should be kept in mind that not only stereochemistry but also the other parameters, such as the sequence of polypeptide and structure together with the specific microenvironments, charge, ionotropy and the presence of specific insoluble macromolecules, can influence the production of a particular polymorph. ${ }^{60-62}$ Scheme 2 shows schematic illustration of the possible conformations of pAsp (a), pGlu (b), and pLys (c) in aqueous solution. Protein structures were used as probes. The selection was made in the protein data bank (www.pdb.org) considering the percentage of secondary structure and narrowing down the choice to calcium binding proteins. Following this, all the amino acids were mutated to obtain the desired polypeptide. The first 40 amino acids from the protein with PDB code 1RTP were used to rebuild the pGlu and pLys conformations, and the peptide regions 12-29, 77-97, 120-135, of the protein with PDB code 1IS4, were used for rebuilding the $\mathrm{pAsp}$ conformation. The $\beta$-pleated sheet structure of pAsp (d) was rebuilt by using the structure of the crystalline region of the $\beta$-pleated sheet of silk (PBD code $1 \mathrm{SLK})$ as a probe and mutating all the amino acids in aspartate. The ribbon indicates $\beta$-sheet regions and the turns indicate random coil and helix conformations. The atoms of the residue side chains are marked by coloured spheres: black for carbon, red for oxygen, and blue for nitrogen. Polyaspartic acid (and to a lesser extent pGlu) interacting with $\mathrm{Ca}^{2+}$ ions, undergoes to a $\beta$-pleated sheet conformation (d). In this structure the polypeptide carboxylate groups can form coordination bonds with the calcite surface calcium ions, thus stabilizing additional crystalline faces instead of the energetically favoured $\{104\}$ ones (e). Variable orientation of the polypeptide carboxylic side groups does not allow to predict (or build a model) the formation of particular calcite faces with the required accuracy. Polylysine interacts with the calcite surface by electrostatic forces and stabilization of any additional face is not expected (f).

\section{THE MODE OF POLYPEPTIDE INTERACTIONS WITH THE CALCITE AND VATERITE SURFACES}

In order to better understand and to corroborate the proposed mode of interactions of synthetic polypeptides (pAsp, pGlu and pLys) with vaterite and calcite surfaces, and to explain the changes in the mechanisms of precipitation processes caused by their presence, the electrokinetic properties of vaterite and calcite seed crystals were analyzed. ${ }^{21,27}$ Figure 12 shows the results of electrophoretic mobility measurements for the both type of crystals dispersed in the saturated calcium carbonate solution with or without a polypeptide added in concentration of $2 \mathrm{ppm}$. For the entire $\mathrm{pH}$ range investigated, the $\zeta$-potentials of pure vaterite and calcite were negative. The addition of acidic polypeptide, pAsp or pGlu, caused the $\zeta$-potential of both polymorphs to become even more negative, showing a poor distinction between $\zeta$-potential of calcite treated with pAsp and pGlu. In distinction from the acidic polypeptides, the presence of pLys, the basic polypeptide, produced a substantial increase in the $\zeta$-potential of calcite seed crystals and the $\zeta$-potential of vaterite seeds became positive. Since the calculated values of isoelectric points 
of the polypeptides used are $\mathrm{p} I_{\mathrm{pAsp}}=1.8, \mathrm{p} I_{\mathrm{pGlu}}=2.1$ and $\mathrm{p} I_{\mathrm{pLys}}=12.3$, the side chain carboxylic groups of $\mathrm{pAsp}$ and pGlu can be considered completely dissociated under the experimental conditions applied. This means that the dissolved acidic polypeptides (pAsp and pGlu) were negatively charged. The side chain amino groups of pLys are protonated under the same conditions, thus accounting for the polypeptide positive net charge. From the results of electrokinetic measurements it is evident that the selected polypeptides were adsorbed on the surfaces of calcite and vaterite independently of their charge. The interactions of positively charged basic polypeptide, pLys, with the negatively charged surfaces of calcite and vaterite crystals are most probably electrostatic, weak and non-specific, continuously releasing and readsorbing on the crystal faces of calcite and vaterite. Consequently, such a polypeptide cannot stabilize specific new crystal faces of calcite with the respect to its energetically favoured $\{104\}$ faces. For pAsp and pGlu a pure electrostatic interaction could occur only at specific crystal faces with a net positive charge. Therefore, it has to be assumed that the majority of their interactions are due to the formation of coordinative bonds between calcium ions at the crystal surface and the side chain carboxylic groups of the polypeptide. Besides, the primary structures of pAsp and pGlu molecules are similar, the only difference being one additional $\mathrm{CH}_{2}$ group in Glu, and their negative charges are also similar $\left(\mathrm{p} K_{\mathrm{a}}(\mathrm{Asp})=3.86\right.$ and $\mathrm{p} K_{\mathrm{a}}(\mathrm{Glu})=4.25$ for the completely dissociated side chain carboxylic groups, $\mathrm{p} K_{\mathrm{a}}(\mathrm{Asp})=2.09$ and $\mathrm{p} K_{\mathrm{a}}(\mathrm{Glu})=2.17$ for $\alpha$-carboxylic groups). Supposing that their interactions with the crystal surfaces are similar, it could indicate that less pAsp than pGlu is adsorbed on vaterite, although the solution concentrations of polypeptides used in experiments were similar $\left(c_{\mathrm{pAsp}}=0.2 \mathrm{ppm} \equiv 1.74 \mu \mathrm{mol} \mathrm{dm}{ }^{-3} ; c_{\mathrm{pGlu}}=\right.$ $0.2 \mathrm{ppm} \equiv 1.55 \mu \mathrm{mol} \mathrm{dm}^{-3} ; c_{\mathrm{pLys}}=0.2 \mathrm{ppm} \equiv 1.56 \mu \mathrm{mol}$ $\mathrm{dm}^{-3}$ ). This seems to be opposite to the report on the greater nucleating ability of pAsp for calcite than that of pGlu. ${ }^{59}$ Nevertheless, different structures of vaterite and calcite should be taken in consideration, and as a consequence, interactions of different geometrics are very likely. In aqueous solutions containing calcium ions, the predicted secondary structure of pAsp presume more extended regions in $\beta$-pleated sheet conformation, whereas pGlu withholds $\alpha$-helix and random coil conformations, as well as, to a lesser extent, the $\beta$-pleated sheet conformation of some distinct regions. ${ }^{59}$ Such a higher conformational flexibility of pGlu could favour interactions of different geometries ${ }^{30}$ with different crystal faces of vaterite, which can justify its preferential adsorption. The morphology of vaterite particles obtained in the experiments did not allow a clear identification of the crystallographic faces at which adsorption of polypeptides occurred. Therefore, no structural model was proposed.

\section{BIOMINERALIZATION RELEVANCE}

The results obtained and the model of interactions between the polypeptides and the CC polymorphs proposed in these studies may certainly be of relevance in explanation of the mechanism of metastable phase(s) formation during the biomineralization processes. Synthetic acidic polypeptides, pGlu and pAsp, were chosen as model acidic polypeptides since the natural acidic glycoproteins extracted from calcitic layers of mollusc shells, vateritic fish otoliths, and ACC from ascidians and spicules are rich in glutamic and aspartic acid residues. These glycoproteins influence and stabilize the vaterite precipitation. ${ }^{63}$ The results presented above corroborate the hypothesis that synthetic acidic polypeptides control precipitation of calcium carbonate polymorphs, vaterite and calcite, and that this is possible only if the electrostatic interactions are supported by coordination bonds. The results also suggest that coordinative interactions of natural glycoproteins may have a significant role in biomineralization. Moreover, the results show that the initial solution supersaturation influences formation of the certain CC polymorph and that the solubility of ACC should be considered as a threshold supersaturation for laboratory studies that mimic biomineralization processes in nature. However, it has to be mentioned that the acidic glycoproteins in biomineralization tend to be adsorbed on surfaces as a part of organic matrix rather than to be dissolved as is the case in this work.

Acknowledgements. The financial support from the Ministry of Science, Education and Sports of the Republic of Croatia (project No. 098-0982904-2951) is gratefully acknowledged.

\section{REFERENCES}

1. H. A. Lowenstam and S. Weiner, On Biomineralization, Oxford University Press, New York, 1989.

2. C. Du, G. Falini, S. Fermani, C. Abbott, and J. Moradian-Oldak, Science 307 (2005) 1450-1454.

3. K. Simkiss and K. Wilbur, in: Biomineralization. Cell Biology and Mineral Deposition, Academic Press, New York, 1989.

4. L. Addadi, S. Raz, and S. Weiner, Adv. Mater. 15 (2003) 959-970.

5. S. Mann, Nature 332 (1988) 119-124.

6. S. Weiner, I. Sagi, and L. Addadi, Science 309 (2005) 1027-1028.

7. L. Addadi, D. Joester, F. Nudelman, and S. Weiner, Chem. -Eur. J. 12 (2006) 981-987.

8. A. Neira-Carrillo, D. F. Acevedo, M. C. Miras, C. A. Barbero, D. Gebauer, H. Cölfen, and J. L. Arias, Langmuir 24 (2008) 12496-12507.

9. D. Gebauer, A. Völkel, and H. Cölfen, Science 322 (2008) 1819-1822.

10. E. M. Pouget, P. H. H. Bomans, J. A. C. M. Goos, P. M. Frederik, G. de With, and N. A. J. M. Sommerdijk, Science 323 (2009) 1455-1458.

11. I. M. Weiss, N.Tuross, L. Addadi, and S. Weiner, J. Exp. Zool. 293 (2002) 478-491. 
12. N. Nassif, N. Pinna, N. Gehrke, M. Antoinetti, C. Jager, and H Cölfen, Proc. Natl. Acad. Sci. U. S. A. 102 (2005) 12653-12655.

13. E. Beniash, J. Aizenberg, , L. Addadi, and S. Weiner, Proc. Roy. Soc. London B 264 (1997) 461-465.

14. Y. Politi, E. Klein, T. Arad, S. Weiner, and L. Addadi, Science 306 (2004) 1161-1164.

15. A. Meibom, J. -P. Cuif, F. Hillion, B. R. Constantz, A. JielletLeclerc, Y. Dauphin, T. Watanabe, and R. B. Dunbar, Geophys. Res. Lett. 31 (2004) L23306.

16. R. Dillaman, S. Hequembourg, and M. Gay, J. Morphol. 263 (2005) 356-374.

17. N. Watabe, V. R. Meenakshi, P. L. Blackwelder, E. M. Kurtz, and D. G. Dunkelberger, in: N. Watabe and K. M. Wilbur (Eds.), University South Carolina Press, Columbia, 1976, pp. 283-308.

18. D. Kralj, Lj. Brečević, A.E. Nielsen, J. Cryst. Growth 104 (1990) 793-800.

19. B. P. Pichon, P. H. H. Bomans, P. M. Frederik, and N. A. J. M. Sommerdijk, J. Am. Chem. Soc. 130 (2008) 4034-4040.

20. Lj. Brečević and A. E. Nielsen, J. Cryst. Growth 98 (1989) 504-510.

21. B. Njegić-Džakula, G. Falini, Lj. Brečević, Ž. Skoko, and D. Kralj, J. Colloid Interface Sci. 343 (2010) 553-563.

22. A. Hesse and G. Sanders, Atlas of Infrared Spectra for Analysis of Urinary Concrements, Georg Thieme Verlag, Stuttgart, 1988.

23. D. Kralj, J. Kontrec, Lj. Brečević, G. Falini, and V. NöthigLaslo, Chem. -Eur. J. 10 (2004) 1647-1656.

24. D. Kralj, Lj. Brečević, and J. Kontrec, J. Cryst. Growth 177 (1997) 248-257.

25. Lj. Brečević, V. Nöthig-Laslo, D. Kralj, and S. Popović, J. Chem. Soc., Faraday Trans. 92 (1996) 1017-1022.

26. N. Cabrera, D. A. Vermilyea, in: R. H. Doremus, B. W. Roberts, and D. Turnbull (Eds.), Growth and Perfection of Crystals, Wiley, New York, 1958.

27. B. Njegić-Džakula, Lj. Brečević, G. Falini, and D. Kralj, Cryst. Growth Des. 9 (2009) 2425-2434.

28. S. A. Markgraf and R. J. Reeder, Am. Miner. 70 (1985) 590-600

29. J. P. R. Villiers, Am. Miner. 56 (1971) 758-767.

30. H. J. Meyer, Z. Kristallogr. 128 (1969) 183-212.

31. S. Mann, J. Inorg. Biochem. 28 (1986) 363-371.

32. S. Mann, D. D. Archibald, J. M. Didymus, T. Douglas, B. R. Heywood, F. C. Meldrum, and N. J. Reeves, Science 261 (1993) 1286-1292.

33. J. Aizenberg, J. Hanson, T. F. Koetzle, S. Weiner, and L. Addadi, J. Am. Chem. Soc. 119 (1997) 881-886.

34. H. H.Teng, P. M. Dove, C. A. Orme, and J. J. De Yoreo, Science 282 (1998) 724-727.

35. Y. Levi, S. Albeck, A. Brack, S. Weiner, and L. Addadi, Chem.Eur. J. 4 (1998) 389-396.

36. G. Falini, S. Fermani, M. Gazzano, and A. Ripamonti, Chem.-
Eur. J. 4 (1998) 1048-1052.

37. C.-S. Choi and Y.-W. Kim, Biomaterials 21 (2000) 213-222.

38. G. Falini, Int. J. Inorg. Mater. 2 (2000) 455-461.

39. J. Wang, Y. Xu, Y. Zhao, Y. Huang, D. Wang, L. Jiang, J. Wu, and D. Xu, J. Cryst. Growth 258 (2003) 367-371.

40. W. T. Hou and Q. L. Feng, J. Cryst. Growth 258 (2003) $402-$ 408.

41. H. Cölfen, Curr. Opin. Colloid Interface Sci. 8 (2003) 23-31.

42. I. W. Kim, J. L. Giocondi, C. Orme, S. Collino, and J. S. Evans, Cryst. Growth Des. 8 (2008) 1154-1160.

43. K. Delak, J. Giocondi, C. Orme, and J. S. Evans, Cryst. Growth Des. 8 (2008) 4481-4486.

44. S. Albeck, J. Aizenberg, L. Addadi, and S. Weiner, J. Am. Chem. Soc. 115 (1993) 11691-11697.

45. J. Aizenberg, S. Albeck, S. Weiner, and L. Addadi, J. Cryst. Growth 142 (1994) 156-164.

46. C. Orme, A. Noy, A. Wierzbicki, M. T. McBride, M. Grantham, H. H. Teng, P. M. Dove, and J. J. De Yereo, Nature 411 (2001) 775-779.

47. D. Kralj, Lj. Brečević, and A. E. Nielsen, J. Cryst. Growth $\mathbf{1 4 3}$ (1994) 267-276.

48. D. Kralj and Lj. Brečević, Colloids Surf. 96 (1995) 287-293.

49. E. Dalas, J. Cryst. Growth 222 (2001) 287-292.

50. P. Malkaj and E. Dalas, J. Cryst. Growth 242 (2002) 405-411.

51. E. Dalas, A. Chalias, D. Gatos, and K. Barlos, J. Colloid Interface Sci. 300 (2006) 536-542.

52. K. Sangwal, Prog. Cryst. Growth Charact. 32 (1996) 3-43.

53. L. Addadi, J. Moradian, E. Shay, N. G. Maroudas, and S. Weiner, Proc. Natl. Acad. Sci. U.S.A. 84 (1987) 2732-2736.

54. Y. Politi, j. Mahamid, H. Goldberg, S. Weiner, and L. Addadi, CrystEngComm 9 (2007) 1171-1177.

55. N. Kubota and J. W. Mullin, J. Cryst. Growth 152 (1995) 203-208.

56. S. Elhadj, E. A. Salter, A. Wierzbicki, J. J. De Yereo, N. Han, and P. M. Dove, Cryst. Growth Des. 6 (2006) 197-201.

57. S. Elhadj, J. J. De Yereo, J. R. Hoyer, and P. M. Dove, Proc. Natl. Acad. Sci. U. S. A. 103 (2006) 19237-19242.

58. J. J. De Yereo, A. Wierzbicki, and P. M. Dove, CrystEngComm 9 (2007)1144-1152.

59. L. Addadi, J. Moradian, E. Shay, N. G. Moroudas, and S. Weiner, Proc. Natl. Acad. Sci. U. S. A. 84 (1987) 2732-2736.

60. B. Gotliv, L. Addadi, and S. Weiner, ChimBioChem 4 (2003) 522-529.

61. B. Gotliv, N. Kessler, J. L. Sumerel, D. E. Morse, N. Tuross, L. Addadi, and S. Weiner, ChimBioChem 6 (2005) 304-314.

62. A. Hernández-Hernández, A. B. Rodríguez-Navarro, J. GómezMorales, C. Jiménez-Lopez, Y. Nys, and J. M. García-Ruiz, Cryst. Growth Des. 8 (2008) 1495-1502.

63. G. Falini, S. Fermani, M. Maritic, S. Vanzo, and G. Zaffino, Eur. J. Inorg. Chem. 1 (2005) 162-167. 